ОСНОВНЫЕ ПРОБЛЕМЫ ПРИ ПРАКТИКЕ АКУШЕРСКОЙ ПРОФЕССИИ В УСЛОВИЯХ СТАЦИОНАРА

DOI: $10.31618 /$ ESU.2413-9335.2020.3.72.631

Радева $C$.

СБАГАЛ "Проф д-р. Стаматов" ЕООД

Варна-Главная акушерка

Георгиева Л.

Катедра по соичильной медицине и организации здравоохранения, Медицинский университет Варна

\title{
MAIN PROBLEMS IN PRACTICING THE PROFESSION OF MIDWIFE IN HOSPITAL CONDITIONS
}

\author{
Radeva $S$. \\ Specialized hospital of obstetrics and gynecolog for active \\ treatment „D-r D. Stamatov”, Varna-Chef midwife \\ Georgieva $\mathbf{L}$. \\ Department of Social Medicine and Healthcare \\ Organization, Medical University of Varna
}

\begin{abstract}
АННОТАЦИЯ
Акушерская профессия требует хорошо осознанной мотивации и понимания сущности профессии со всеми обязанностями рабочего процесса и потребностями пациентов. В Болгарии профессия больше не привлекательна для новых кадров. Все больше и больше разрыв между условиями и принятой моделью работы с растущими требованиями пациентов. В настоящей статье представлены результаты исследования среди 173 акушерок из пяти больниц в разных городах страны относительно основных проблем практики, а также соответствия их предварительным ожиданиям с реальным рабочим процессом.

\section{SUMMARY}

The obstetric profession requires a well-informed motivation and understanding of the nature of the profession with all the responsibilities of the work process and the needs of the patients. In Bulgaria, the profession is no longer attractive for new staff. There is a growing gap between the conditions and the adopted model of work with the increasing demands of patients. This article presents the results of a survey of 173 midwives from five hospitals in different cities across the country about the main problems in practice and the compliance of their expectations with the actual work process.
\end{abstract}

Ключевые слова: акушерка, больница, обязанности, проблемы, трудовая среда

Key words: midwife, hospital, responsibilities, problems, work environment

Введение: Профессия акушера - это "коммуникативная" профессия (5) „Одна из ее основных задач связана с умением акушерки строить эффективные профессиональные отношения, мотивировать женщину к активному участию и содействию в процессе акушерской помощи, поддерживать систематическую эмоциональную связь с ней, достигать необходимой эмоциональной поддержки, уметь снижать боль и беспокойство, внушать уверенность, учить и помогать ей в поддержании соответствующего поведения в отношении здоровья. Деятельность акушерок в Болгарии определяется постановлением номер 1 Министерства здравоохранения от 08.02.2011 (1).

Да бъдеш акушерка днес изисква не само добри клинични умения, но и широко разбиране за социалните и емоционални промени, които жената преживява преди и след раждането. Професията на акушерката изисква отговорно отношение, дисциплина, знания и редица отговорности за грижите за деца и новородени (2). Изисква се изграждане на умения (3) и комбиниране на научни знания с способност за чувствителна комуникация с пациентите (4), за да се осигури най-добрата грижа за майката по време на процеса на раждане, както и след (6).

Цель: Цель настоящего исследования состоит в том, чтобы выяснить основные проблемы акушерок при их практике в больничных условиях и соответствовать их предварительным ожиданиям с реальным рабочим процессом.

Материал и методы: было проведено исследование среди 173 работающих акушерок в больничных структурах из разных городов: Варна, Плевен, Велико Тырново и Тутракан по вопросам практики профессии. Используемые методы являются документальными, социологическими (прямой анонимный опрос) и статистическими. Обработка данных осуществляется с помощью статистического пакета СПСС Вер. 19.0.

Результаты и обсуждение: почти половина респондентов работают в медицинских учреждениях в городе. Варна, остальные-в городах Плевен, Велико Тырново и Тутракан (рис.1). 


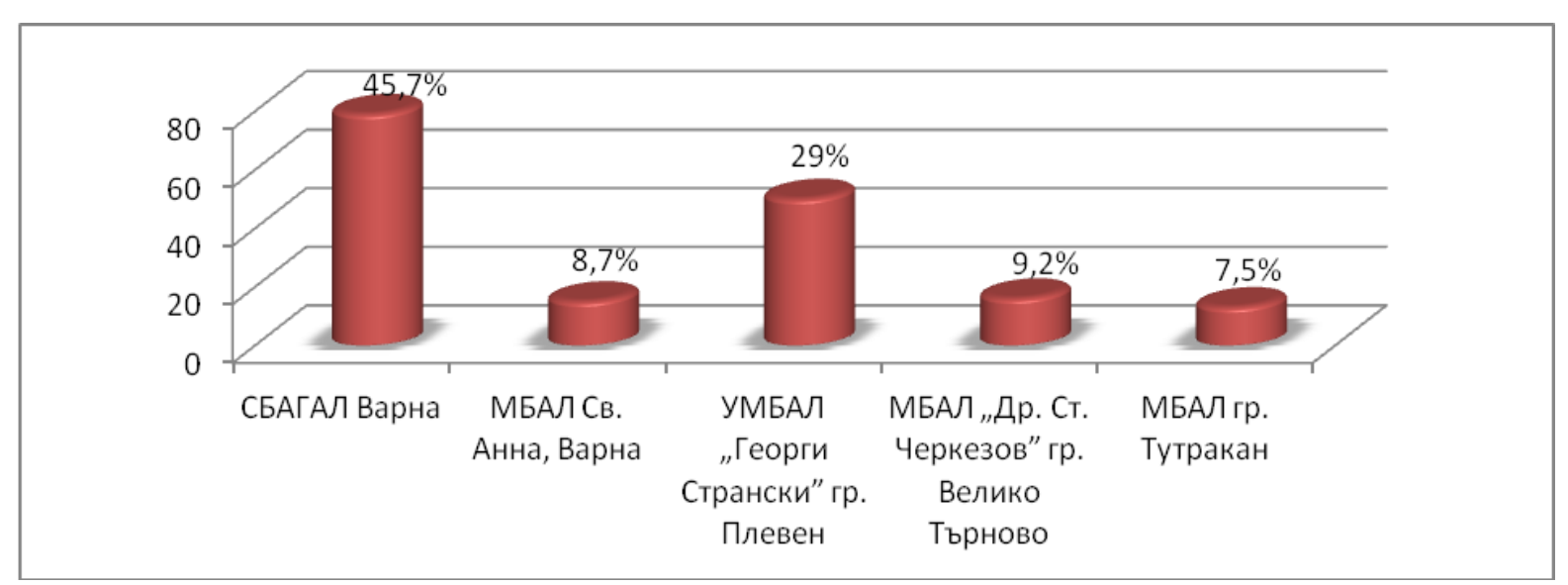

Рис.1. Распределение респондентов по городам и медицинским учреждениям.

На вопрос, Соответствует ли реальность на рабочем месте 111 (64\%) опрошенных акушерок удовлетворительно, что указывает на то, что они имеют реальное представление о характере работы, принимают акушерскую помощь в качестве призвания и сделали осознанный выбор для реализации в профессиональном аспекте. Более $66 \%$ опрошенных установили высокую нагрузку на рабочую среду (рис.2). В свободных ответах большая часть из них разделяет то, что основные трудности касаются специфики работы и деятельности по секторам, освоения новых навыков, многих обязательств и большого объема информации. Наиболее интенсивными и загруженными являются сектора в хирургическом блоке, родильных залах, интенсивных неонатологических отделениях и реанимации.

Рис. 2. Степень нагрузки акушерок на рабочем месте.

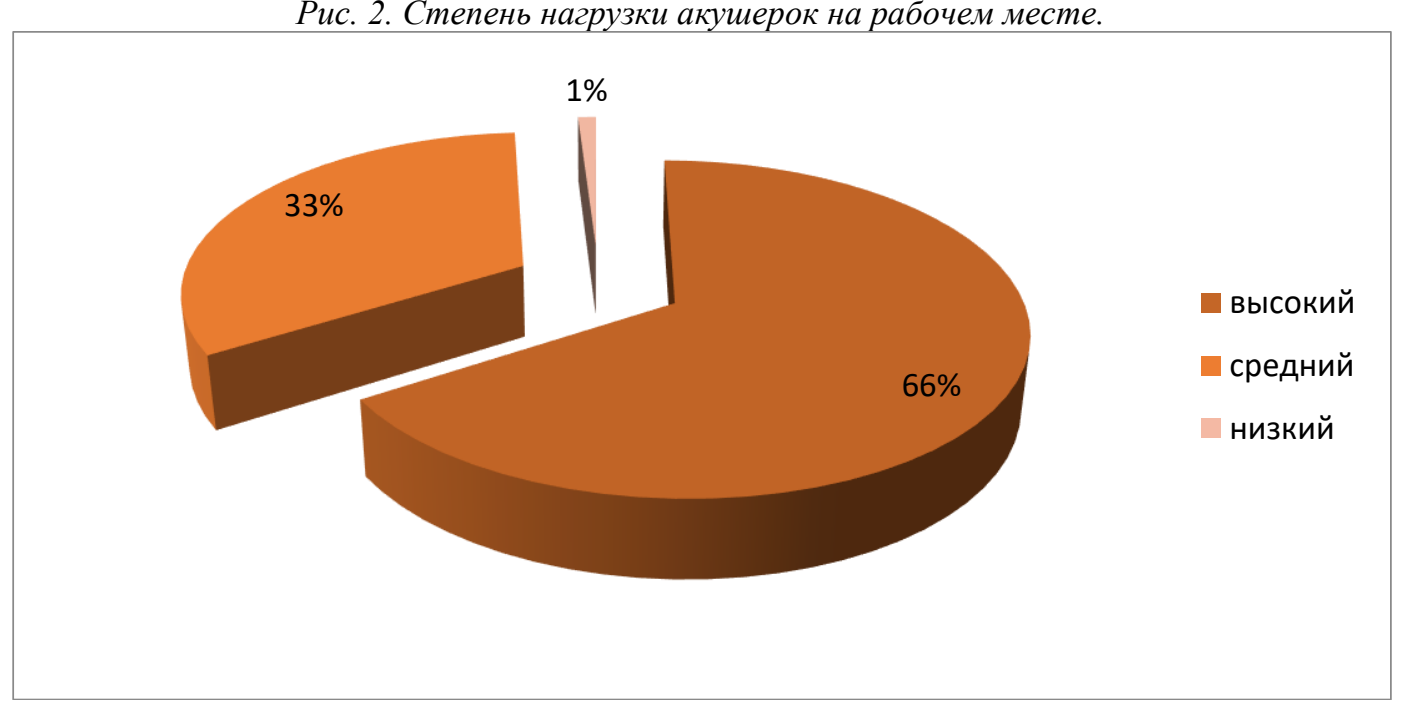

Респонденты поделились тем, что из-за нехватки квалифицированных медицинских специалистов частые дежурства приводят к усталости, снижению работоспособности, апатии, снижению качества выполнения рутинных обязанностей. Большая часть (более $56 \%$ ) работает на втором рабочем месте, что приводит к перенапряжению, усталости, что является предпосылкой синдрома „профессионального ожога" (бернаут). Другие указывают на непрерывный объем информации, который должен быть сведен к повседневной работе, что препятствует работе команды и препятствует организации работы. Изменения в нормативной базе превращают оказание акушерской помощи в Администрирование деятельности и остается все меньше и меньше времени для общения с пациентами, с возможностью понимания и развития эмпатического отношения беременных и родов. При практике акушерской профессии в лечебных структурах происходит процесс общения, с пониманием. Акушерка должна уметь владеть коммуникативными навыками в своей деятельности, умениями говорить, навыками прослушивания. В своей работе она сталкивается с неприятными ощущениями, которые напрягают и напрягают обстановку, которую разделяют 72 процента опрошенных.

Вызванный

необходимостью самосовершенствования, 112 (65\%) респондентов поделились тем, что им нужны тренинги в своей работе (рис. 3). 


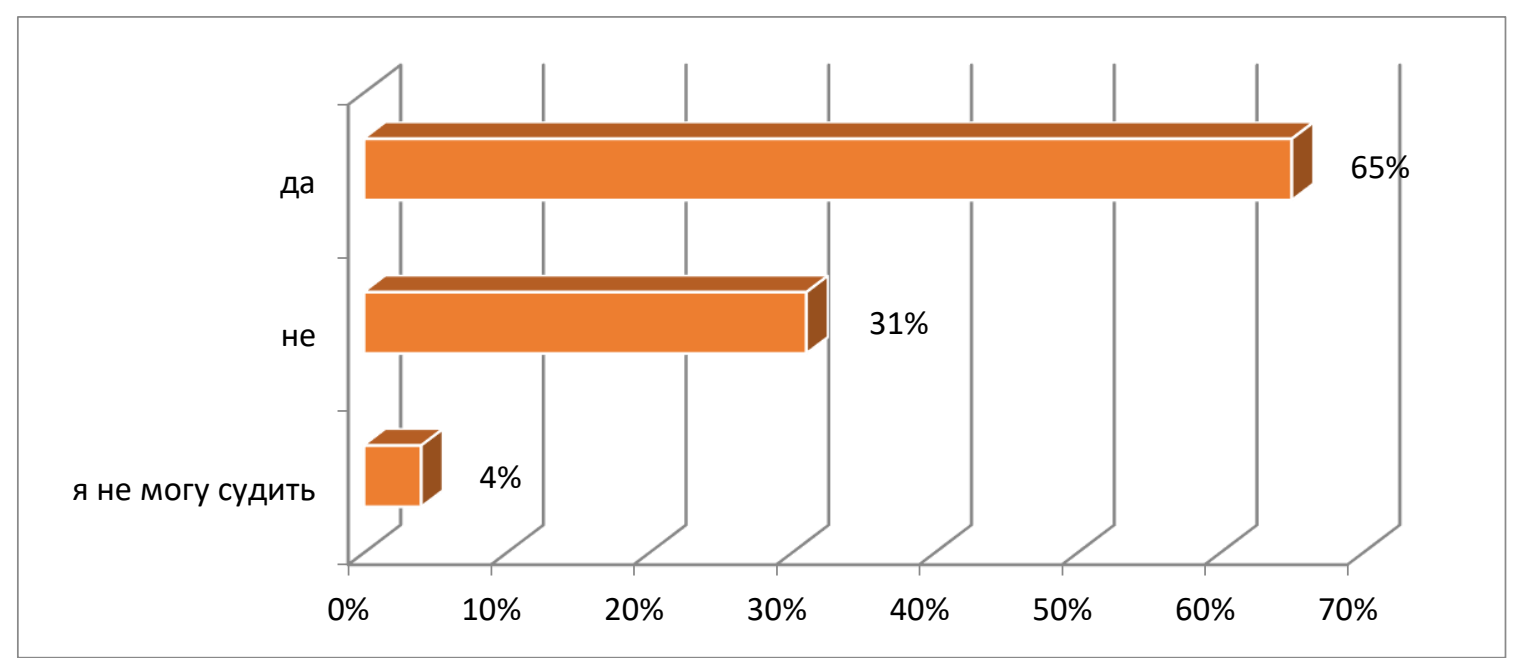

Рис. 3. Необходимость дополнительных тренингов.

Основное внимание в необходимых учебных курсах уделяется респондентам: методы работы с командой на 37\%, для специальных практических акушерских колледжей на $32,9 \%$, курсы по улучшению общения на $16,2 \%$ и обучение иностранным языкам на 10,4\%. С такими курсами работающие акушерки из больничных структур делают акцент на желании улучшить свои навыки и профессиональные качества.

Основной проблемой является система оплаты-161 (93\%) опрошенных определяют как ведущую проблему низкой оплаты труда и отсутствие механизмов ее повышения. Законодательно на отраслевом уровне устанавливаются пороги оплаты труда медицинских специалистов, которые не адекватны обязанностям и нагрузкам. Именно это является одной из причин оттока из профессии, что приводит к нагрузке работающих специалистов с дополнительными рабочими сменами, что приводит к стрессу и напряжению. Для 145 (84\%) респондентов отсутствие коллективности является еще одной большой проблемой на рабочем месте, что затрудняет повседневную деятельность при оказании акушерско-гинекологической и неонатологической помощи.

В-третьих, возникает проблема конфликтов и напряженной обстановки. Отношение, с которым акушерки сталкиваются со стороны высшего персонала, микроклимат в отделениях, конфликтах и грубом отношении, оказывает негативное влияние уже в первые трудовые дни и затрудняет их адаптацию к рабочей среде. При оказании медицинской помощи акушерки высказывают мнение, что они часто попадают в конфликтные ситуации $(49,1 \%)$, что еще больше затрудняет выполнение их профессиональной деятельности (Табл. 1).

Причины конфликтов различны:

- часто личного характера, связанные с скудностью людских и материальных ресурсов;

- с пациентами и их близкими, как в последнее время агрессия и насилие в отношении медиков происходит из-за нетерпимости людей и отсутствия механизмов охраны труда в организациях. Это результат деперсонализации и тенденции к негативному отношению пациентов к медицинским работникам в больничных структурах, что ежедневно приводит к конфликтам и является предпосылкой насилия;

- напряженность в оказании медицинской помощи - право выбора женщин на способ родов, отказ от вмешательства во время родов, не осознавая необходимости в медицинской помощи, и не введя законодательно необходимой ответственности. Пациенты имеют право выбора во всех отношениях, при осознании рисков и осуществляющих процессов, этот выбор должен регулироваться ответственно и законодательно. Необходимо ввести акушерскую модель, регулировать Стандарт для осуществления акушерской помощи, а также единый Стандарт акушерства и гинекологии;

- каналы связи для передачи и получения информации;

- с коллегами, связанными с организацией работы, различным видением и различным поведением в работе. 
Табл. 1

Проблемы на рабочем месте для работников больницы акушерки

\begin{tabular}{|c|c|c|c|}
\hline № & Определенные проблемы & $\begin{array}{c}\text { Количество } \\
\text { опрошенных }\end{array}$ & $\begin{array}{c}\text { Относительный } \\
\text { раздел }\end{array}$ \\
\hline 1 & Отсутствие обратной связи с руководством & 12 & $7 \%$ \\
\hline 2 & Смутно определенные обязательства & 97 & $56 \%$ \\
\hline 3 & Смутно поставленные задачи & 101 & $58 \%$ \\
\hline 4 & Отсутствие команды на работе & 145 & $84 \%$ \\
\hline 5 & Отсутствие системы оплаты & 161 & $93 \%$ \\
\hline 7 & Конфликтная и напряженная обстановка & 134 & $77 \%$ \\
\hline
\end{tabular}

Сумма процентов составляет более 100\%, потому что респонденты давали более одного ответа.

В своих свободных ответах больничные акушерки разделяют то, что они чувствуют себя недооцененными, а работа в неадекватных условиях еще больше затрудняет проблемы на рабочем месте. Опрошенные высказывают мнение, что необходимо улучшить микроклимат на рабочем месте, создать возможность хорошей гигиены человеческих отношений, проведя раннее посредничество в возникших проблемах и конфликтах, что приведет к сплочению команд и повысит их удовлетворенность и мотивацию к работе. Готовность респондентов заключалась в том, чтобы новинки были сведены к рабочей среде поэтапно со стороны прямых руководителей, которые могли бы объяснить и реализовать новые положения наилучшим и рациональным образом в работе, а не чисто административным, что на данный момент затрудняет их работу. Отсутствие материально технических средств, аппаратуры и возможности работы в соответствии с компетенциями вызывает напряжение и углубляет условия, при которых происходит рабочий процесс. От них требуется и ожидает, что они будут постоянно самосовершенствоваться, так как в процессе работы выполняют разные роли-от профессионала, до психолога, наставника, руководителя команды и т. д.н. Эти обстоятельства закономерно приводят к нехватке акушерок в системе здравоохранения, особенно для практики в больничных условиях. Из этого наиболее благоприятствуемым является частный сектор из за предлагаемых условий работы и оплаты. Акушерки разделяют мнение (более 75\%) о необходимости проведения мероприятий по внедрению акушерской модели ухода, потому что акушерская помощь является личной, требует поощрения и поддержки матери, близких, она информативна. Акушерка может применять модель ухода, основанную исключительно на фактических данных, - знание родового и послеродового процесса, с соответствующим использованием технологий для достижения отличных результатов.

Вывод: Акушерская профессия трудна, требует ответственного отношения, дисциплины, знаний и ряда обязанностей по уходу за детьми и новорожденными. Процесс оказания акушерской помощи и общения является постоянным, без последующей длительной обратной связи о качестве работы, потому что уход потребляется немедленно, и часто нет времени для пересмотра решений или вариантов выбора, при этом ошибки недопустимы. Наблюдение за беременной женщиной в больнице, ведение родов, уход за новорожденным и матерью и многое другое. являются акушерскими мероприятиями, в которых акушер не может реализовать без эффективного взаимодействия с пациентами, с коллегами и другими членами команды.

Напряженная повседневная жизнь, отсутствие признания и неоценимая акушерская деятельность часто приводят к отсутствию доверия между акушером и пациентом. Основные проблемы на рабочем месте являются административными, которые препятствуют тому, чтобы акушерки работали спокойно и в полной мере демонстрировали свои знания и навыки.

\section{Литература}

1. Наредба №1 от 08.02.2011 г. за професионалните дейности, които медицинските сестри, акушерките, асоциираните медицински специалисти и здравните асистенти могат да извършват по назначение или самостоятелно. ДВ, бр. 15 от 18.02.2011, изм. ДВ, бр. 50 от 01.07.2011.

2. Jones S. Ethics in Midwifery. $2^{\text {nd }} \mathrm{Ed}, 2000$.

3. Homer C, Brodie P, Leap N. Midwifery Continuity of Care - A Practical Giude. Elsevier, 2008.

4. Page LA, McCandlish R. The New Midwifery - Science and Sensitivity in Practice. $2^{\text {nd }}$ Ed, 2006.

5. Responsibilities of the Midwife's Birth Assistant. Believe Midwifery Services. LLC, 2014.

6. Wickham S. Midwifery: Best Practice. Vol. 5, 2008.

Адрес за кореспонденция: Светлана Радева

СБАГАЛ „Проф. д-р Д. Стаматов“ ЕООД бул. "Цар освободител" № 150 гр. Варна 9000 